\title{
Differential Effects of High-Temperature Stress on Nuclear Topology and Transcription of Repetitive Noncoding and Coding Rye Sequences
}

\author{
D. Tomás J. Brazão W. Viegas M. Silva \\ Centro de Botânica Aplicada à Agricultura, Secção de Genética, Instituto Superior de Agronomia, \\ Technical University of Lisbon, Lisbon, Portugal
}

\section{Key Words}

High temperature $\cdot$ Nuclear topology $\cdot$ rDNA $\cdot$ Rye $\cdot$

Subtelomeric sequences $\cdot$ Transcription

\begin{abstract}
The plant stress response has been extensively characterized at the biochemical and physiological levels. However, knowledge concerning repetitive sequence genome fraction modulation during extreme temperature conditions is scarce. We studied high-temperature effects on subtelomeric repetitive sequences (pSc200) and 45S rDNA in rye seedlings submitted to $40^{\circ} \mathrm{C}$ during $4 \mathrm{~h}$. Chromatin organization patterns were evaluated through fluorescent in situ hybridization and transcription levels were assessed using quantitative real-time PCR. Additionally, the nucleolar dynamics were evaluated through fibrillarin immunodetection in interphase nuclei. The results obtained clearly demonstrated that the pSc200 sequence organization is not affected by high-temperature stress (HTS) and proved for the first time that this noncoding subtelomeric sequence is stably transcribed. Conversely, it was demonstrated that HTS treatment induces marked rDNA chromatin decondensation along with nucleolar enlargement and a significant increase in ribosomal gene transcription. The role of noncoding and coding repetitive rye sequences in the plant stress response that are suggested by their clearly distinct behaviors is discussed. While the hetero-
\end{abstract}

chromatic conformation of pSc200 sequences seems to be involved in the stabilization of the interphase chromatin architecture under stress conditions, the dynamic modulation of nucleolar and rDNA topology and transcription suggest their role in plant stress response pathways.

Copyright $\odot 2012$ S. Karger AG, Basel

All organisms, particularly plants, are exposed to environmental stress conditions, induced by biotic or abiotic factors that negatively impact growth, development and reproduction [Inostroza-Blancheteau et al., 2010]. For plants, as sessile organisms, the ability to sense and react appropriately to environmental stress situations, such as extreme temperatures, drought and high salinity, is particularly important. Responses and adaption at the molecular, physiological and biochemical levels have been extensively studied in several plant species, revealing a multidimensional network system [reviewed in Niedziela et al., 2012]. However, little is known about the impact of temperature stress on the repetitive fraction of plant genomes, which is strongly implicated in genome structure and function [Morgante, 2006]. Our work aims to integrate the knowledge concerning heat stress consequences in chromatin topology and the transcriptional dynamics of repetitive sequences - rDNA and subtelomeric pSc200 sequences - in rye (Secale cereale L.) seedlings.

\section{KARGER}

Fax +4161306 1234

E-Mail karger@karger.ch

www.karger.com (c) 2012 S. Karger AG, Basel

$1424-8581 / 13 / 1392-0119 \$ 38.00 / 0$

Accessible online at:

www.karger.com/cgr
Manuela Silva

Centro de Botânica Aplicada à Agricultura, Secção de Genética

Instituto Superior de Agronomia, Technical University of Lisbon

Tapada da Ajuda, PT-1349-017 Lisbon (Portugal)

E-Mail manuelasilva@isa.utl.pt 
The large rye genome is mostly composed of repetitive sequences (92\%) [Bartos et al. 2008], of which subtelomeric sequences and $45 \mathrm{~S}$ rDNA correspond to $12-18 \%$ [Bedbrook et al., 1980] and 0.32\% [Appels et al., 1980; Rogers and Bendich, 1987] of the whole genome, respectively. Rye subtelomeric repetitive sequences are structurally very important due to their role in chromosome stability, nuclear organization and homologous recombination [Vershinin et al., 1995]. These repetitive sequences were also recently implicated in genome evolution, being more prevalent in crop cultivars than in wild ones [Tamura et al., 2011]. Such sequences assume a heterochromatic organization and are subdivided into 3 families (pSc119.2, pSc200 and pSc250) [Vershinin et al., 1995]. Of these families, the $\mathrm{pSc} 200$ sequences are the most representative, comprising $2.5 \%$ of the rye genome and being present in all rye subtelomeric chromosome domains [Vershinin et al., 1995]. Recently [Tamura et al., 2011], rye chromosome C-bands, initially described by Gill and Kimber [1974], were shown to colocalize with fluorescent in situ hybridization (FISH) signals obtained with pSc119.2, pSc74, pSc34, pSc200, and pSc250 probes. In rye, a Rabl nuclear organization with centromeres and telomeres located in opposite hemispheres was described [Aragon-Alcaide et al., 1996] as in other species with large genomes, such as wheat (Triticum ssp.) and barley (Hordeum vulgare L.) [Aragon-Alcaide et al., 1996; Dong and Jiang, 1998; Mikhailova et al., 2001].

rDNA 45S units are clustered in tandem in the nucleolar organizing regions (NORs) localized on rye chromosome 1R. Throughout the cell cycle rye NORs are characterized by 2 chromatin domains, a more decondensed euchromatic domain and a highly compacted heterochromatic domain [Caperta et al., 2002]. Transcription of rDNA occurs in the nucleolus, a less DNA-dense nuclear domain where each rye ribosomal locus can assume 3 distinct conformations: perinucleolar knobs, perinucleolar knobs with intranucleolar projections or, most rarely, perinucleolar and intranucleolar knobs connected by decondensed chromatin [Caperta et al., 2002]. Rye rDNA nuclear topology is affected by both nucleolar chromosome structural alterations and induced DNA hypomethylation [Caperta et al., 2002, 2007].

The most well-characterized temperature stress response in plants is the induction of proteins with chaperone functions, especially several large families of heatshock proteins (HSPs) [reviewed in Kosová et al., 2011]. A consistent increase in the synthesis of distinct HSPs was detected in coleoptiles and in roots of 3-day-old rye seedlings after a 4 -hour period of $40^{\circ} \mathrm{C}$ heat shock, with the rye HSP profile being similar to those observed in other cereals, such as wheat, triticale and barley [Necchi et al., 1987]. High- and low-temperature stress in rye also increases catalase photoinhibition, reducing its activity as well as the synthesis of protein D1 from photosystem II [Feierabend et al., 1992; Hertwig et al., 1992].

Long periods of heat stress have recently been shown to induce the activity of the usually silenced repetitive sequences in Arabidopsis thaliana and their reversion to silence after a return to normal temperatures [Pecinka et al., 2010; Tittel-Elmer et al., 2010]. A marked decondensation of $180 \mathrm{bp}$ centromeric and $5 \mathrm{~S}$ rDNA sequences after $30 \mathrm{~h}$ at $37^{\circ} \mathrm{C}$ was also observed [Pecinka et al., 2010; Tittel-Elmer et al., 2010]. Ribosomal 45S chromatin decondensation was also detected in cereals (Oryza sativa L. and T. aestivum L.) after stresses from high temperature and high salinity, which showed additional effects on nuclear topology [Santos et al., 2011].

We have characterized the alterations affecting coding and noncoding rye repetitive sequences induced by hightemperature stress (HTS, $4 \mathrm{~h}$ at $40^{\circ} \mathrm{C}$ ), including chromatin organization (assessed through FISH) and transcriptional levels (evaluated by quantitative real-time PCR RT-qPCR). This analysis revealed for the first time the transcription of pSc200 noncoding sequences, assuming similar levels in untreated and treated plants. Contrastingly, rDNA transcription levels are markedly increased by heat stress, along with a significant enhancement of the nucleolar region evaluated through fibrillarin immunodetection. This behavior was also correlated with distinct interphase chromatin dynamics under heat stress, as rDNA decondensation was unraveled after HTS, whereas pSc200 chromatin organization remained unaffected. Thus, the results in this report contribute to a comprehensive understanding of repetitive sequence involvement in nuclear topology remodeling and gene expression control under environmental stress conditions.

\section{Material and Methods}

Plant Material and High-Temperature Treatment

Rye seeds ( $S$. cereale, $2 \mathrm{n}=14, \mathrm{RR}$ ), kindly provided by Prof. Neil Jones (Aberystwyth, Wales University), were germinated at $22^{\circ} \mathrm{C}$ in Petri dishes with moistened filter paper in the dark. Thus, 3-4-day-old seedlings were submitted to HTS as follows: the temperature was increased $2{ }^{\circ} \mathrm{C} / \mathrm{h}$ from 22 to $40^{\circ} \mathrm{C}$ and then maintained for $4 \mathrm{~h}$ at $40^{\circ} \mathrm{C}$. Leaves from at least 3 seedlings per treatment (control and HTS) for each cytogenetic analysis were collected, washed and fixed. The materials to be used for FISH were fixed in ethanol/acetic acid solution $(3: 1 \mathrm{v} / \mathrm{v})$ for $16 \mathrm{~h}$ at room temperature and stored at $-20^{\circ} \mathrm{C}$. Alternatively, leaves to be used in 
immunochemistry assays were fixed in $0.2 \%$ formaldehyde in $1 \times$ PBS with $0.1 \%$ triton X100 (v/v) for 30 min, maintained with $100 \%$ methanol overnight at room temperature, and then stored at $-20^{\circ} \mathrm{C}$.

For RNA extraction, the seedlings were also kept in moistened filter paper in growth chambers on an $8 \mathrm{~h}$ dark $\left(15^{\circ} \mathrm{C}\right) / 16 \mathrm{~h}$ light $\left(22^{\circ} \mathrm{C}\right)$ cycle for 10 days and were then submitted to the HTS treatment previously described. Leaves from at least 3 seedlings per treatment (control and HTS) were stored separately at $-80^{\circ} \mathrm{C}$.

\section{Fluorescent in situ Hybridization}

Fixed leaves were digested with pectinase/cellulase in $1 \times \mathrm{EB}$ for $1 \mathrm{~h}$ and $30 \mathrm{~min}$ at $37^{\circ} \mathrm{C}$, and squashes were performed in $60 \%$ glacial acetic acid. The pSc200 and 45S rDNA probes labeled with digoxigenin-dUTP or biotin-dUTP (Roche, Gipf-Oberfrick, Switzerland) were produced by PCR using the following described primers. For the pSc200 probe, pSc200for 5'-TCTTTGATCACCGTTTCTTCG-3' and pSc200rev 5'-CCCCACCCATGTATGGATAA- $3^{\prime}$ primers were used. To produce the $45 \mathrm{~S}$ rDNA probe, 3 pairs of primers were used to amplify 3 distinct fragments of the rDNA coding regions - 25S1for 5'-CTTAGTAACGGCGAGCGAAC-3' and 25S1rev 5'-CACTTGGAGCTCTCGATTCC-3', 25S2for 5'-AACTCACCTGCCGAATCAAC-3' and 25S2rev 5'-GCCGAAGCTCCCACTTATC-3', and 18Sfor 5' ACTGTGAAACTGCGAATGG-3' and 18Srev $5^{\prime}$-CCCGACTGTCCCTGTTAATC-3' (online suppl. fig. 1; for all online suppl. material, see www.karger.com/doi/10.1159/000343754).

FISH was performed as previously described [Silva et al., 2008]. Nuclei were counterstained with 4',6-diamidino-2-phenylindole hydrochloride (DAPI) in Citifluor antifade mounting medium (AF1; Agar Scientific, Essex, UK). Samples were examined using a Zeiss Axioskop 2 epifluorescence microscope, images were obtained using a Zeiss AxioCam digital camera and selected images were processed using Photoshop after quantification.

The following parameters were evaluated through quantification of raw images using ImageJ software: nuclear area, number of pSc200 signals, pSc200 global area, average area per pSc200 signal, pSc200 area/nuclear area, number of rDNA signals, rDNA total area, rDNA area/nuclear area, and major rDNA signal distance. Statistical analysis was performed using Student's test to compare averages and using the $\chi^{2}$ test to compare frequency distributions.

\section{Immunocytochemistry}

Fixed rye leaves were digested with pectinase/cellulase for $2 \mathrm{~h}$ and $30 \mathrm{~min}$, and squashes were obtained as described for FISH. However, after removing the cover slip, the squashes were immediately placed in $1 \times$ PBS for at least 5 min and then fixed with $4 \%$ formaldehyde in $1 \times$ PBS (v/v) for $10 \mathrm{~min}$. Blocking was performed with $8 \%$ BSA in $1 \times$ PBS triton $0.1 \%(\mathrm{v} / \mathrm{v})$ for $30 \mathrm{~min}$, followed by a rapid wash with $1 \times$ PBS. Primary antibody for fibrillarin (ab4566 Abcam, Cambridge, UK), 1:500 dilution in 1× PBS, was used at $4{ }^{\circ} \mathrm{C}$ overnight followed by a rapid wash in $1 \times$ PBS. Secondary antibody [C2181 Sigma Anti-Mouse IgG, whole molecule, $\mathrm{F}(\mathrm{ab}$ ') Cy3-conjugated] 1:200 dilution in 1× PBS was used for $1 \mathrm{~h}$ at $37^{\circ} \mathrm{C}$. Nuclei were counterstained as described for the FISH experiments, as were microscope examination, image capture and processing.

The following parameters were evaluated through quantification of raw images using ImageJ software: nucleolar total area, nucleolar area ratio, frequencies of nuclei with different nucleoli number, and average nucleoli number per nuclei. Statistical analysis was performed using Student's t test to compare averages and using $\chi^{2}$ test to compare frequency distributions.

\section{Quantitative Real-Time PCR}

Total RNA extraction was performed using Kit Frozen, hard consistency, or RNase-rich tissue sample preparation protocol from the RNAqueous Kit (Ambion, Austin, Tex., USA) following the manufacturer's recommendations. After verifying the quality and concentration through gel electrophoresis and spectrophotometry, the RNA was submitted to RQ1 RNase-Free DNase (Promega, Madison, Wisc., USA) digestion for $1 \mathrm{~h}$ at $37^{\circ} \mathrm{C}$ following the manufacturer's recommendations. cDNA synthesis was performed with random primers following the DyNAmo cDNA Synthesis kit (Finnzymes, Vantaa, Finland) instructions. To individualize single monomers from pSc200 tandem repeated sequence, a $B f a I$ (Finnzymes) enzymatic digestion of cDNA was performed according to the supplier's instructions. The expected single band was confirmed through agarose gel electrophoresis.

RT-qPCR was performed with a HS SYBR qPCR Kit (Finnzymes, Vantaa, Finland) accordingly to Silva et al. [2008] using the following primers: rDNAfor 5'-CGGCACGTACGTCTGGTG-3' and rDNArev 5'-AGACAAGCATATGACTACTGGCAG-3', pSc200for 5'-TCTTTGATCACCGTTTCTTCG-3' and pSc200rev 5'-ACGTGCGTGGAAAATTCTG-3' (online suppl. fig. 1). Actin was used as a control gene using the following primers: actinfor 5'-GCTGGATTCTGGTGATGGTGTGAG-3' and actinrev $5^{\prime}$ CAATGAGAGATGGCTGGAAGAGGAC-3'. All cDNAs were analyzed in 3 replicates for control and HTS treatment at each of following dilutions: 1:20, 1:100 and 1:200 for pSc200, 1:10 and 1:20 for rDNA, and 1:10 and 1:20 for the actin control. Each PCR mix containing forward and reverse primers ( $0.1 \mathrm{pM}$ each) was amplified over 40 cycles ( $10 \mathrm{~s}$ of denaturation at $94^{\circ} \mathrm{C}, 30 \mathrm{~s}$ of annealing at $60^{\circ} \mathrm{C}$ and $30 \mathrm{~s}$ at $72^{\circ} \mathrm{C}$ for extension). Upon completion, the PCR products were separated by $1 \%$ agarose gel electrophoresis and detected by ethidium bromide staining.

Melting curves were performed to ensure the amplification of single products and to estimate their melting temperatures. The RT-qPCR of pSc200 amplified a single cDNA product with the expected size of $208 \mathrm{bp}$ and a melting temperature of $82^{\circ} \mathrm{C}$ (fig. $1 \mathrm{~B}$, C). In the same experiments, the actin control amplified equal quantities of a single product of approximately $350 \mathrm{bp}$ with a melting temperature $(\mathrm{Tm})$ of $84^{\circ} \mathrm{C}$ in control and treated rye seedlings (fig. 1A, C). rDNA RT-qPCR analysis was performed through the amplification of a fragment consisting of part of the transcribed spacer sequence and part of the $18 \mathrm{~S}$ coding sequence (between +828 and $+1181 \mathrm{bp}$, online suppl. fig. 1B). Using actin as control, a single cDNA product was amplified with the expected size of $350 \mathrm{bp}$ and a melting temperature of $86^{\circ} \mathrm{C}$ (fig. $1 \mathrm{~B}, \mathrm{C}$ ).

Quantification analysis was performed using the $\Delta \Delta \mathrm{Ct}$ method to analyze the levels of pSc200 and rDNA transcription. The mean actin cDNA threshold cycle $(\mathrm{Ct})$ was used to calculate each $\Delta \mathrm{Ct}(\Delta \mathrm{Ct}=\mathrm{Ct} \mathrm{pSc} 200$ or $\mathrm{rDNA}-$ mean $\mathrm{Ct}$ actin $)$ associated with 3 replicates of both dilutions. The comparison of $\Delta \mathrm{Ct}$ values obtained for the control and HTS was performed using Student's t test. To compare between the control and HTS, $\Delta \Delta \mathrm{Ct}$ values $(\Delta \Delta \mathrm{Ct}=\Delta \mathrm{Ct}$ HTS - mean $\Delta \mathrm{Ct}$ control) were calculated for both repetitive sequences analyzed. These values were utilized to calculate the fold variation in transcription $\left(2^{-\Delta \Delta C t}\right)$. 


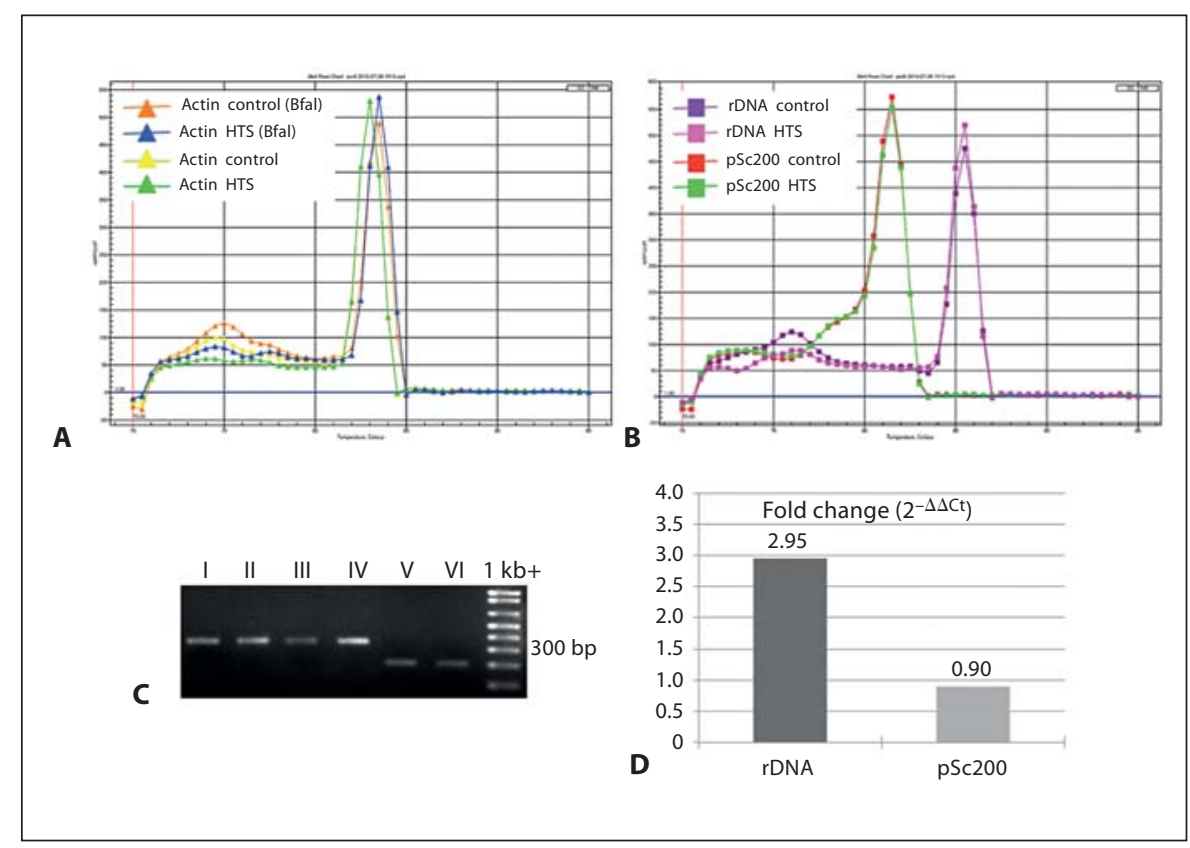

Fig. 1. Subtelomeric sequence and rDNA transcription in control and HTS-treated rye seedlings. A Melt curves of cDNA isolated from rye amplified with actin primers. A single melt peak with $\mathrm{Tm}=83^{\circ} \mathrm{C}$ observed both in the control seedlings (yellow) and in seedlings submitted to HTS (green) indicate a single amplification product. In cDNA digested with $B f a I$, only a single peak with similar Tm is also observed in the control (orange) and HTS (blue). B Melt curves of cDNA isolated from rye amplified with rDNA (pink and purple) and pSc200 (green and red) primers. A single melt peak (rDNA: $\mathrm{Tm}=85.5^{\circ} \mathrm{C}, \mathrm{pSc} 200$ : $\mathrm{Tm}=81^{\circ} \mathrm{C}$ ) observed in both the control seedlings (purple for rDNA and red for pSc200) and seedlings submitted to HTS (pink for rDNA and

\section{Results and Discussion}

\section{HTS Affects Rye Chromosome Nuclear Topology}

Rye nuclear topology analysis in leaf cells was performed through the characterization of chromatin conformation on DAPI-stained nuclei and also through FISH analysis of pSc200 subtelomeric sequences (521 bp rye tandem repeat sequence, accession number Z50039 [Vershinin et al., 1996]). Distinct DAPI-positive knobs corresponding to heterochromatic domains colocalized with pSc200 signals were observed (fig. 2A, B). pSc200 and pSc250 subtelomeric repeats were previously localized to heterochromatic regions [Vershinin et al., 1995; Cuadrado and Jouve, 2002]; however, the organization and disposition of pSc200 sequences was never characterized in interphase nuclei from rye leaves. A polarized arrangement of pSc200 signals, consistently clustered in one nu- green for pSc200) indicate a single amplification product. C RTqPCR products separated by gel electrophoresis. I and II: actin primers, control cDNA and HTS cDNA, respectively; III and IV: rDNA primers, control cDNA and HTS cDNA, respectively; V and VI: pSc200 primers, control cDNA and HTS cDNA, respectively, both digested with $B f a \mathrm{I}$. Molecular weight marker $1 \mathrm{~kb}+$ D Transcription levels of rDNA and pSc200 in control and HTS seedlings. RT-qPCR threshold cycles (Ct) were equilibrated with actin for control and HTS $(\Delta \mathrm{Ct})$. The mean $\Delta \mathrm{Cts}$ of 3 replicates of 3 control and HTS cDNA dilutions were used to calculate $\Delta \Delta$ Ct. The graph illustrates the associated fold changes in transcription $\left(2^{-\Delta \Delta C t}\right)$ in the control and HTS-treated seedlings.

clear pole, was observed in rye leaf nuclei. This pSc200 localization confirms the telomeric Rabl organization previously described in the root tip nuclei of other species with large genomes [Aragon-Alcaide et al., 1996; Dong and Jiang, 1998].

Quantitative image analysis of pSc200 FISH signals using ImageJ software revealed an average number of 10 signals per nuclei (table 1). Gill and Kimber [1974] described 14 heteropycnotic knobs, corresponding to major subtelomeric C-bands, per Giemsa-stained rye root tip interphase nucleus. Those subtelomeric C-bands observed in metaphase chromosomes colocalize with the pSc200 signals [Gill and Kimber, 1974; Vershinin et al., 1995]. However, pSc200 FISH signals are located in virtually all rye subtelomeric domains, depending on the line considered [Vershinin et al., 1996; Alkhimova et al., 1999; Fu et al., 2010; Książczyk et al., 2011]. Thus, the reduced 
Table 1. Average values \pm standard deviation of nuclear area, number and area of pSc200 FISH signals, area of individual pSc200 FISH signal and ratio between pSc200 area and nuclear area in leaf nuclei from control seedlings and seedlings subjected to HTS

\begin{tabular}{llllll}
\hline & $\begin{array}{l}\text { Nuclear area } \\
\mu \mathrm{m}^{2 *}\end{array}$ & $\begin{array}{l}\text { No. of pSc200 } \\
\text { signals }\end{array}$ & $\begin{array}{l}\text { pSc200 global } \\
\text { area, } \mu \mathrm{m}^{2}\end{array}$ & $\begin{array}{l}\text { Area of individual } \\
\text { pSc200 signals, } \mu \mathrm{m}^{2 *}\end{array}$ & $\begin{array}{l}\mathrm{pSc} 200 \text { area/ } \\
\text { nuclear area, \% }\end{array}$ \\
\hline Control & $114.44 \pm 77.64$ & $9.88 \pm 5.69$ & $26.72 \pm 8.82$ & $3.40 \pm 2.16$ & $25.85 \pm 7.90$ \\
HTS & $156.85 \pm 54.45$ & $16.02 \pm 7.37$ & $29.44 \pm 10.33$ & $2.15 \pm 1.30$ & $19.46 \pm 6.07$ \\
\hline
\end{tabular}

$\mathrm{N}=$ Total number of nuclei observed. * Parameters significantly different between control and HTS ( $\mathrm{t}$ test, $\mathrm{p}<0.01$ ).

number of pSc200 FISH observed here in rye leaves and previously observed through C-banding in root tips [Gill and Kimber, 1974] most likely result from the overlapping of chromosome arms. In fact, colocalization of subtelomeric domains was previously described in rye chromosomes introgressed in wheat [Santos et al., 2002].

HTS versus control comparative analysis of pSc200 showed a marked increase in the average number of signals per nuclei $(16)$ and a significantly higher $(\mathrm{p}<0.01)$ nuclear area (HTS: $156.85 \mu \mathrm{m}^{2}$, control: $114.44 \mu \mathrm{m}^{2}$ ). These results suggest an overall chromatin reorganization induced by HTS involving a higher individualization of chromosome and subtelomeric domains. Moreover, the significant $(\mathrm{p}<0.01)$ decrease observed in the average area per pSc200 signal (from $3.39 \mu \mathrm{m}^{2}$ in untreated to $2.15 \mu^{2}$ in HTS-treated) also suggests a higher individualization of subtelomeric domains. Concurrently, no significant increase $(\mathrm{p}>0.1)$ was detected in the total average area of pSc200 FISH signals per nuclei $\left(26.72 \mu \mathrm{m}^{2}\right.$ in untreated and $29.44 \mu \mathrm{m}^{2}$ in treated nuclei). A decrease in rye subtelomeric domain overlapping induced by DNA hypomethylation was also described in rye chromosomes in a wheat background [Santos et al., 2002].

RT-qPCR evaluation of pSc200 subtelomeric sequence proved for the first time that the $\mathrm{pSc} 200$ subtelomeric repetitive sequence is actively transcribed in rye. Until now, transcription of subtelomeric repetitive sequences was only described in rice through RNA blot analysis and primer extension analysis [Wu et al., 1994] and for rye Bchromosome-specific sequences through RT-qPCR [Carchilan et al., 2007; Pereira et al., 2009]. Control versus HTS transcription fold variation analysis $\left(2^{-\Delta \Delta \mathrm{Ct}}=0.90\right.$, graphic representation in fig. 1D) showed that the pSc200 sequence transcription level is not significantly (Student's $\mathrm{t}$ test, $\mathrm{p}=0.07$ ) affected by HTS. This result is in accordance with the evidence that $\mathrm{pSc} 200$ chromatin organization is not significantly ( $p>0.1)$ modified, revealing stable pSc200 tandem repetitive sequence behavior under

Rye Repetitive Sequence Modulation by Temperature

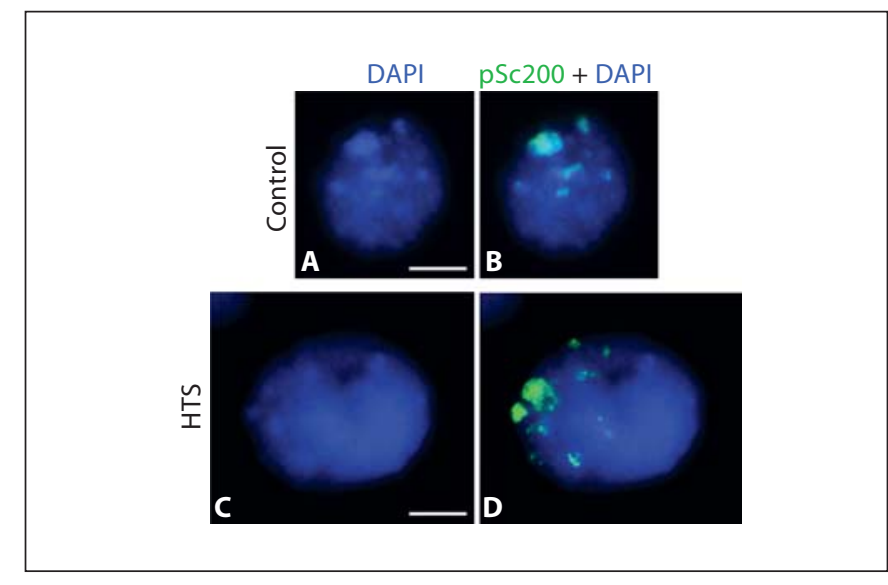

Fig. 2. Subtelomeric chromatin organization in control and HTStreated rye nuclei. pSc200 subtelomeric probe in situ hybridization of leaf nuclei of control seedlings ( $\mathbf{A}$ and $\mathbf{B})$ and seedlings submitted to HTS (C and D); DAPI-stained (A and $\mathbf{C})$ and DAPI and probe green signal merged (B and $\mathbf{D})$. Scale bar $=5 \mu \mathrm{m}$.

HTS. Thus, we suggest that $\mathrm{pSc} 200$ sequences may be included in the 'conformational DNA' fraction, as suggested by Nagl and Schmitt [1985] regarding actively transcribed condensed chromatin domains. Additionally, we are tempted to speculate that the detection of putative microRNAs in pSc200 transcripts may suggest their potential role in the maintenance of interphase heterochromatic domains. In fact, pSc200 transcripts reveal high homology (between 85 and 87\%) with rice and Sorghum microRNAs (online suppl. fig. 2); one of them - rice osaMIR2921 (accession MI0013263) - is implicated in the plant stress response [Sanan-Mishra et al., 2009]. The Superior repetitive element dispersed throughout rye chromosomes was also shown by Northern blots to be actively transcribed, and their RNA stem structure was suggested to indicate a possible functional role [Tomita et al., 2009].

Cytogenet Genome Res 2013;139:119-127 
Table 2. Average values \pm standard deviation of the number and area of rDNA FISH signals, ratio between rDNA area and nuclear area and major rDNA signal distance from control seedlings and seedlings subjected to HTS

\begin{tabular}{lllll}
\hline & No. of rDNA signals & rDNA total area, $\mu \mathrm{m}^{2 *}$ & rDNA area/nuclear area, \%* & Major rDNA signals distance, $\mu \mathrm{m}$ \\
\hline Control & $2.08 \pm 0.34(51)$ & $2.42 \pm 0.77(51)$ & $2.49 \pm 1.04(51)$ & $4.42 \pm 2.30(56)$ \\
HTS & $2.35 \pm 1.47(58)$ & $2.85 \pm 0.93(58)$ & $1.96 \pm 0.78(58)$ & $5.14 \pm 3.07(60)$ \\
\hline
\end{tabular}

Total number of nuclei observed are in parentheses. * Parameters significantly different between control and HTS ( $\mathrm{t}$-test, $\mathrm{p}<0.01)$.

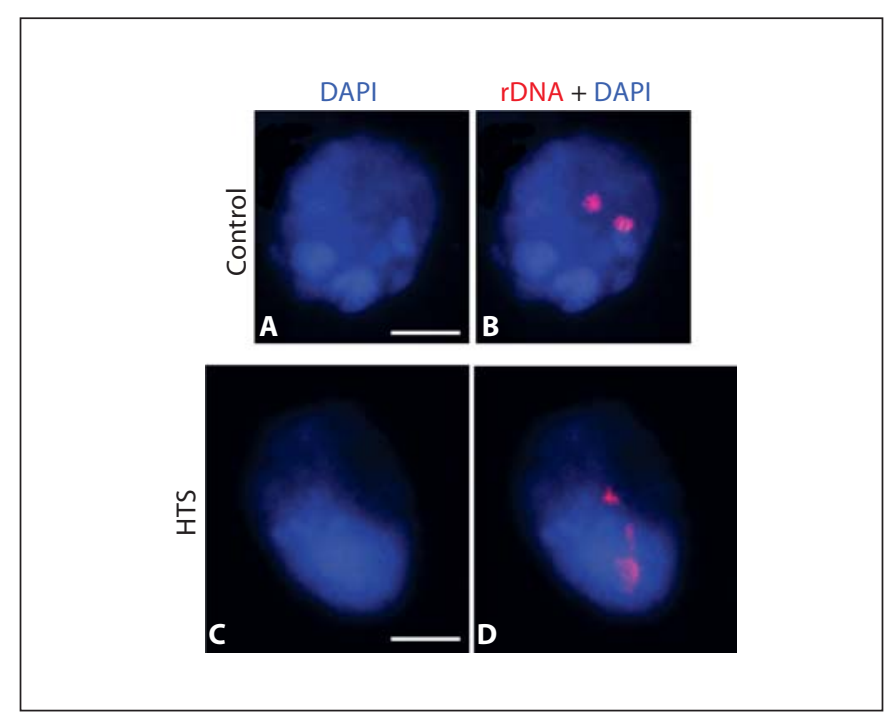

Fig. 3. rDNA chromatin organization in control and HTS-treated rye nuclei. Images of $45 \mathrm{~S}$ rDNA in situ hybridization of leaf nuclei of control seedlings (A and B) and seedlings submitted to HTS (C and D); DAPI-stained (A and $\mathbf{C}$ ) and DAPI and red probe signal merged (B and $\mathbf{D})$. Scale bar $=5 \mu \mathrm{m}$.

rDNA Organization and Expression Levels Are Affected by HTS

To evaluate rDNA functional and structural alterations induced by temperature stress in $45 \mathrm{~S}$ rDNA repetitive coding sequences, FISH-probed interphase nuclei from control and HTS-treated rye seedlings were analyzed using ImageJ software. Additionally, nucleolar morphology and dynamics were characterized through in situ immunolocalization with a fibrillarin antibody used as a nucleolar marker [Houmani and Ruf, 2009].

In the majority $(90 \%)$ of nuclei from untreated seedlings, only 2 perinucleolar knobs of 45 S ribosomal DNA were present (fig. $3 \mathrm{~A}, \mathrm{~B}$ ), which is consistent with the existence of 2 NORs allocated to the chromosome 1R pair. In addition to the 2 perinucleolar knobs, smaller intra- nucleolar rDNA signals and rDNA filaments of decondensed chromatin were observed in $10 \%$ of the nuclei analyzed $(n=51)$ (fig. $3 B, C)$, in agreement with a previous description of rye root-tip nuclei by Caperta et al. [2002]. No significant $(p>0.1)$ alteration in the frequency of nuclei with only $245 \mathrm{~S}$ knobs (85\%) was observed after hightemperature treatment $(n=58)$.

Contrastingly, a significant $(\mathrm{p}<0.01)$ increase in the average number of rDNA FISH signals per nucleus (from 2.08 to 2.35 , table 2) was observed after HTS, reflecting a higher number of additional intranucleolar FISH signals (fig. 3C, D). In species in which each NOR is usually observed as one condensed knob per chromosome, as in rye [Caperta et al., 2002] and A. thaliana [Pontes et al., 2003], additional FISH signals indicate that more rDNA is located inside the nucleolus and that internal decondensation has occurred within the NORs [Earley et al., 2006]. Moreover, intranucleolar rDNA spots colocalize with BrUTP incorporation in wheat nuclei [Silva et al., 2008] and are associated with an epigenetic marker linked to euchromatin (tri-methyl Lysine 4 of histone H3) in A. suecica [Earley et al., 2006]. Accordingly, the average area per nucleus of rDNA FISH signals is significantly $(\mathrm{p}<0.01)$ higher in treated seedlings $\left(2.85 \mu \mathrm{m}^{2}\right)$ compared to untreated ones $\left(2.42 \mu \mathrm{m}^{2}\right)$ (table 2$)$. Both of the revealed alterations in rDNA organization patterns - the higher number of FISH signals and global rDNA area increase - suggest an enhancement of ribosomal gene activity mediated by HTS.

Nucleolar dynamics were also evaluated using in situ immunolocalization with a fibrillarin antibody (table 3). Fibrillarin is an essential nucleolar protein involved in rRNA processing that has been isolated from various organisms, including yeast, mammals and Arabidopsis [reviewed in Pih et al., 2000]. This nucleolar protein is highly conserved and has been extensively used as a nucleolar marker in both animals and plants [Pih et al., 2000; Houmani and Ruf, 2009]. The evaluation of the average number of nucleoli per nucleus revealed a significant increase 
Table 3. Average values \pm standard deviation of the ratio between nucleolar area and nuclear area, nucleolar area, $\%$ of nuclei with different nucleoli number and nucleoli number per nuclei in leaves nuclei from control seedlings and seedlings subjected to HTS

\begin{tabular}{llllll}
\hline & $\begin{array}{l}\text { Nucleolar area/nuclear } \\
\text { area, \%* }\end{array}$ & $\begin{array}{l}\text { Nucleolar total } \\
\text { area, } \mu \mathrm{m}^{2 *}\end{array}$ & \multicolumn{2}{l}{$\begin{array}{l}\text { \% of nuclei with different } \\
\text { nucleoli number }\end{array}$} & Nucleoli number per nuclei** \\
\cline { 1 - 2 } Control & $13.14 \pm 4.90(60)$ & $15.50 \pm 5.91(60)$ & $81.0(145)$ & $19.0(34)$ & $1.19 \pm 0.39(179)$ \\
HTS & $21.53 \pm 7.16(76)$ & $33.37 \pm 15.81(76)$ & $73.3(326)$ & $26.7(119)$ & $1.27 \pm 0.44(445)$ \\
\hline
\end{tabular}

Total number of nuclei observed are in parentheses.

* Parameters significantly different between control and HTS ( $\mathrm{t}$ test, $\mathrm{p}<0.01$ ).

** Parameter significantly different between control and HTS ( $t$ test, $\mathrm{p}<0.05$ ).

(1.19 in control and 1.27 in HTS, $\mathrm{p}<0.05$ ) induced by HTS. An increase in the frequency of nuclei with 2 nucleoli was also observed in treated leaf nuclei $(19.0 \%$ in the control and $26.7 \%$ in HTS). A higher nucleoli number due to a temperature increase from 25 to $37^{\circ} \mathrm{C}$ was also observed by Leitch et al. [1995] in nuclei from the root-tips of wheat cv. Beaver with a rye chromosome translocation (1BL/1RS). Cell cycle arrest in early G1 phase, which decreases the characteristic nucleolar fusion usually associated with cell cycle progression, was suggested to be responsible for the nucleolar number increase [Leitch et al., 1995]. In fact, a delay in the cell cycle caused by high temperatures was also observed in Saccharomyces cerevisiae [Rowley et al., 1993] and in mammalian cells [Kuhl and Rensing, 2000].

To assess ribosomal chromatin nuclear disposition alterations induced by temperature stress, the distance between the 2 major rDNA knobs, corresponding to the 2 rye rDNA loci, was evaluated (table 2). No significant difference $(p>0.1)$ was detected between the average distances scored in the control $(4.42 \mu \mathrm{m})$ and HTS-treated nuclei $(5.14 \mu \mathrm{m})$. Previously, an increase in $5 \mathrm{~S}$ knob distance was described in rice root-tip nuclei exposed to high temperatures [Santos et al., 2011]. However, rDNA allocation depends upon a higher order determinant that results from the functional linkage between rDNA genes and nucleoli. In fact, Pecinka et al. [2004] proved through chromosome painting using BAC probes that although random homolog disposition has a role in root and leaf nuclei from $A$. thaliana, an enhanced association was observed between rDNA-bearing homologous chromosomes. The authors correlated those results with the frequent attachment of multiple NORs to a single nucleolus present in the majority of interphase nuclei. We propose that the physical constraint imposed by the structural

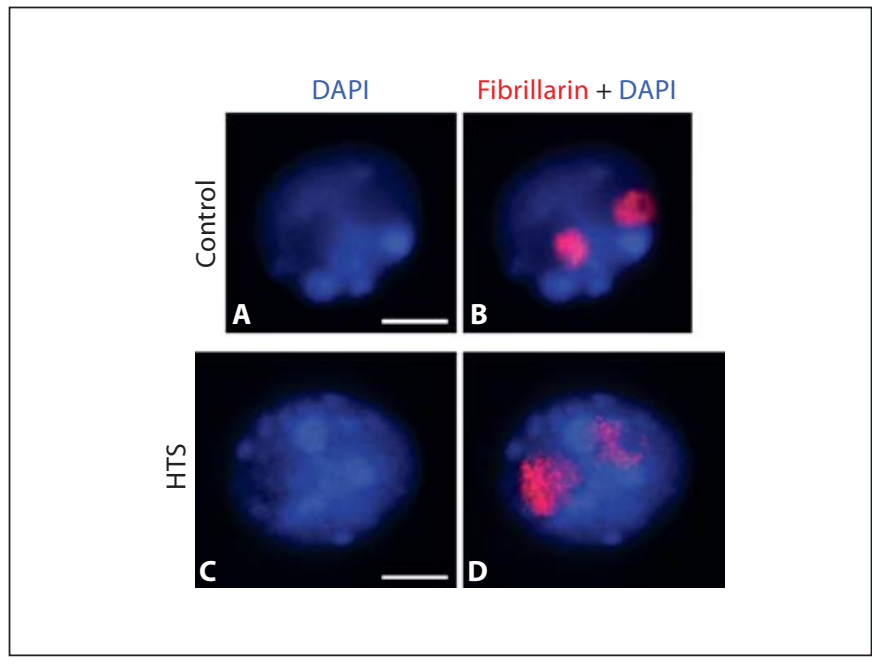

Fig. 4. Nucleoli detection in control and HTS-treated rye nuclei. Fibrillarin immunolabeling of leaf nuclei of control seedlings (A and B) and seedlings submitted to HTS (C and D); DAPIstained ( $\mathbf{A}$ and $\mathbf{C})$ and DAPI and fibrillarin antibody red signal merged (B and $\mathbf{D})$. Scale bar $=5 \mu \mathrm{m}$.

connection between rye NORs and a single nucleolus observed in the majority of rye leaf nuclei may therefore be responsible for the maintenance of the rDNA spatial relationships, even under stress conditions.

The analysis of nucleolar dynamics (table 3) showed that control and HTS nucleolar/nuclear area ratios were significantly different (13.14 and $21.53 \%$, respectively; $\mathrm{p}<0.01)$ due to a significant $(\mathrm{p}<0.01)$ nucleolar enlargement induced by HTS (from 15.50 to $33.37 \mu \mathrm{m}^{2}$ ). Furthermore, the nucleoli of HTS-treated cells presented a more granular morphology (fig. 4D), suggesting that nucleoli enlargement may result from a differential increase 
in the granular component. Such nucleoli quantitative and morphological changes may result from a decrease in rRNA transport from the nucleus to the cytoplasm, as occurs in the nucleoli of rye root-tips submitted to temperature stress [Olszewska et al., 1988], or may otherwise result from enhanced rDNA transcription levels induced by heat stress situations.

To address this question, the quantification of rDNA transcription levels was performed through RT-qPCR. The comparison of $\Delta \mathrm{Ct}$ values obtained for the control (3.43) and HTS (4.37) using Student's t test revealed a significant $(\mathrm{p}<0.04)$ increase in rDNA expression represented by a fold change variation of $2^{-\Delta \Delta C t}=2.95$. We suggest that this drastic enhancement of rDNA transcription is correlated with the significant enlargement in nucleolar area also detected.

HTS impacts on rDNA chromatin organization and transcription patterns denoted their entirely different behaviors under temperature stress in comparison to pSc200 subtelomeric sequence. Nuclear topology parameters clearly showed ribosomal chromatin decondensation and nucleolar enlargement, along with a significant increase in rDNA transcription levels. Altogether, these results suggest the central role of rDNA in the plant response to stressful environmental conditions related with an increase in the ribosome requirement. Most research in plants describes expression profile alterations caused by several abiotic stresses such as abscisic acid, salt, water deficit, cold, and heat [Mochida et al., 2006; Swindell et al., 2007; Zeller et al., 2009; Tamura et al., 2011]. Additionally, those alterations showed that the number of upregulated genes is clearly higher than the number of downregulated genes [Qin et al., 2008; Hu et al., 2009]. This unbalanced situation may justify the higher rDNA transcription level required. rDNA decondensation in- duced by HTS can result from a decrease in nucleosome assembly, as suggested by the result from the abiotic stress conditions [Pecinka et al., 2010; Tittel-Elmer et al., 2010] that detected the reactivation of gene expression after long HTS ( 30 and $15 \mathrm{~h}$ at $37^{\circ} \mathrm{C}$, respectively). However, our results revealed differences between the noncoding and coding repetitive sequence chromatin dynamics detected as soon as $4 \mathrm{~h}$ after the shift to $40^{\circ} \mathrm{C}$. The increase in HSP synthesis detected in rye seedlings was shown to also occur shortly after a 4 -hour period at $40^{\circ} \mathrm{C}$ [Necchi et al., 1987].

Our results clearly suggest marked behavioral differences between coding and noncoding repetitive sequences that most likely reflect their distinct roles in the plant pathways involved in the stress response. We propose that pSc200 unaltered chromatin organization patterns in treated and untreated rye nuclei indicate their role in the maintenance of chromosome and nuclei structural function. Moreover, pSc200 stable transcription levels under temperature may denote a possible involvement of microRNAs in the nucleotypic role of telomeric-associated sequences in chromatin architecture.

\section{Acknowledgements}

We would like to thank Perry Gustafson for his stimulating discussions, helpful comments and careful proofreading of the manuscript. Furthermore, we thank Heike Sprenger for her assistance in nucleoli evaluation, Luísa Carvalho for RT-qPCR assistance, Augusta Barão for technical support and Ana Costa for her help in microRNA searching. João Brazão was funded by a BII fellowship from the CBAA Research Unit, Diana Tomás was funded by a fellowship from the Research Project PTDC/BIABEC/101964/2008 and the work was financed by PTDC/BIABEC/101964/2008 research project, Fundação para a Ciência e a Tecnologia (FCT).

\section{References}

Alkhimova AG, Heslop-Harrison JS, Shchapova AI, Vershinin AV: Rye chromosome variability in wheat-rye addition and substitution lines. Chromosome Res 7:205-212 (1999).

Appels R, Gerlach WL, Dennis ES, Swift H, Peacock WJ: Molecular and chromosomal organization of DNA-sequences coding for the ribosomal-RNAs in cereals. Chromosoma 78:293-311 (1980).

-Aragon-Alcaide L, Miller T, Schwarzacher T, Reader S, Moore G: A cereal centromeric sequence. Chromosoma 105:261-268 (1996).
Bartos J, Paux E, Kofler R, Havrankova M, Kopecky D, Suchankova P, Safar J, Simkova H, Town CD, Lelley T, Feuillet C, Dolezel J: A first survey of the rye (secale cereale) genome composition through BAC end sequencing of the short arm of chromosome 1r. Bmc Plant Biol 8 (2008).

Bedbrook JR, Jones J, Odell M, Thompson RD, Flavell RB: Molecular description of telomeric heterochromatin in secale species. Cell 19:545-560 (1980).
Caperta AD, Neves N, Morais-Cecílio L, Malhó $\mathrm{R}$, Viegas W: Genome restructuring in rye affects the expression, organization and disposition of homologous rDNA loci. J Cell Sci 115:2839-2846 (2002).

Caperta AD, Neves N, Viegas W, Pikaard CS, Preuss S: Relationships between transcription, silver staining, and chromatin organization of nucleolar organizers in Secale cereale. Protoplasma 232:55-59 (2007).

-Carchilan M, Delgado M, Ribeiro T, CostaNunes P, Caperta A, et al: Transcriptionally active heterochromatin in rye $\mathrm{B}$ chromosomes. Plant Cell 19:1738-1749 (2007). 
Cuadrado A, Jouve N: Evolutionary trends of different repetitive DNA sequences during speciation in the genus Secale. J Hered 93: 339-345 (2002).

Dong F, Jiang J: Non-Rabl patterns of centromere and telomere distribution in the interphase nuclei of plant cells. Chromosome Res 6:551558 (1998).

Earley K, Lawrence RJ, Pontes O, Reuther R, Enciso AJ, et al: Erasure of histone acetylation by Arabidopsis HDA6 mediates large-scale gene silencing in nucleolar dominance. Gene Dev 20:1283-1293 (2006).

Feierabend J, Schaan C, Hertwig B: Photoinactivation of catalase occurs under both hightemperature and low-temperature stress conditions and accompanies photoinhibition of photosystem-II. Plant Physiol 100: 1554-1561 (1992).

Fu SL, Tang ZX, Ren ZL: Inter- and intra-genomic transfer of small chromosomal segments in wheat-rye allopolyploids. J Plant Res 123: 97-103 (2010).

Gill BS, Kimber G: The giemsa c-banded karyotype of rye. Proc Natl Acad Sci USA 71:12471249 (1974).

-Hertwig B, Streb P, Feierabend J: Light dependence of catalase synthesis and degradation in leaves and the influence of interfering stress conditions. Plant Physiol 100:15471553 (1992).

Houmani JL, Ruf IK: Clusters of basic amino acids contribute to RNA binding and nucleolar localization of ribosomal protein L22. PLoS One 4:e5306 (2009).

- Hu WH, Hu GC, Han B: Genome-wide survey and expression profiling of heat shock proteins and heat shock factors revealed overlapped and stress specific response under abiotic stresses in rice. Plant Sci 176:583-590 (2009).

Inostroza-Blancheteau C, Soto B, Ibanez C, Ulloa P, Aquea F, et al: Mapping aluminum tolerance loci in cereals: a tool available for crop breeding. Electron J Biotechn 13 (2010).

Kosová K, Vitámvás P, Prášil IT, Renaut J: Plant proteome changes under abiotic stress - contribution of proteomics studies to understanding plant stress response. J Proteomics 74:1301-1322 (2011).

Książczyk T, Apolinarska B, Kulak-Książczyk S, Wiśniewska H, Stojałowski S, Łapiński M: Identification of the chromosome complement and the spontaneous $1 \mathrm{R} / 1 \mathrm{~V}$ translocations in allotetraploid Secale cereale $\times$ Dasypyrum villosum hybrids through cytogenetic approaches. J Appl Genet 52:305-311 (2011).

Kuhl NM, Rensing L: Heat shock effects on cell cycle progression. Cell Mol Life Sci 57:450463 (2000).

Leitch AR, Glyn M, Kingham K, Quinn M, Aragon-Alcaide LF, et al: The dynamic organisation of interphase nuclei during cell differentiation and with changing cell activity, in Brandham PE, Bennett MD (eds): Kew Chromosome Conference IV, pp 83-94 (1995).
Mikhailova EI, Sosnikhina SP, Kirillova GA, Tikholiz OA, Smirnov VG, et al: Nuclear dispositions of subtelomeric and pericentromeric chromosomal domains during meiosis in asynaptic mutants of rye (Secale cereale L.). J Cell Sci 114:1875-1882 (2001).

Mochida K, Kawaura K, Shimosaka E, Kawakami N, Shin-I T, et al: Tissue expression map of a large number of expressed sequence tags and its application to in silico screening of stress response genes in common wheat. Mol Genet Genomics 276:304-312 (2006).

Morgante M: Plant genome organisation and diversity: the year of the junk! Curr Opin Biotechnol 17:168-173 (2006).

Nagl W, Schmitt HP: Transcription of repetitive DNA in condensed plant chromatin. Mol Biol Rep 10:143-146 (1985).

Necchi A, Pogna NE, Mapelli S: Early and late heat-shock proteins in wheats and other cereal species. Plant Physiol 84:1378-1384 (1987).

Niedziela A, Bednarek PT, Cichy H, Budzianowski G, Kilian A, Aniol A: Aluminum tolerance association mapping in triticale. BMC Genomics 13:67 (2012).

Olszewska MJ, Kuran H, Marciniak K: Relationship between resumption of rRNA transport into cytoplasm after cold treatment and progression through the cell-cycle in root-meristem cells. Environ Exp Bot 28:375-380 (1988).

Pecinka A, Schubert V, Meister A, Kreth G, Klatte $\mathrm{M}$, et al: Chromosome territory arrangement and homologous pairing in nuclei of Arabidopsis thaliana are predominantly random except for NOR-bearing chromosomes. Chromosoma 113:258-269 (2004).

Pecinka A, Dinh HQ, Baubec T, Rosa M, Lettner N, Scheid OM: Epigenetic regulation of repetitive elements is attenuated by prolonged heat stress in Arabidopsis. Plant Cell 22: 3118-3129 (2010).

Pereira HS, Barão A, Caperta A, Rocha J, Viegas W, Delgado M: Rye Bs disclose ancestral sequences in cereal genomes with a potential role in gametophyte chromatid segregation. Mol Biol Evol 26:1683-1697 (2009).

$\checkmark$ Pih KT, Yi MJ, Liang YS, Shin BJ, Cho MJ, et al: Molecular cloning and targeting of a fibrillarin homolog from Arabidopsis. Plant Physiol 123:51-58 (2000).

Pontes O, Lawrence RJ, Neves N, Silva M, Lee JH, et al: Natural variation in nucleolar dominance reveals the relationship between nucleolus organizer chromatin topology and rRNA gene transcription in Arabidopsis. Proc Natl Acad Sci USA 100:11418-11423 (2003).

Qin DD, Wu HY, Peng HR, Yao YY, Ni ZF, et al: Heat stress-responsive transcriptome analysis in heat susceptible and tolerant wheat (Triticum aestivum L.) by using wheat genome array. BMC Genomics 9:432 (2008).

Rogers SO, Bendich AJ: Ribosomal-RNA genes in plants - variability in copy number and in the intergenic spacer. Plant Mol Biol 9:509520 (1987).
Rowley A, Johnston GC, Butler B, Wernerwashburne M, Singer RA: Heat shock-mediated cell cycle blockage and G1 cyclin expression in the yeast Saccharomyces cerevisiae. Mol Cell Biol 13:1034-1041 (1993).

-Sanan-Mishra N, Kumar V, Sopory SK, Mukherjee SK: Cloning and validation of novel miRNA from basmati rice indicates cross talk between abiotic and biotic stresses. Mol Genet Genomics 282:463-474 (2009).

Santos AP, Abranches R, Stoger E, Beven A, Viegas W, Shaw PJ: The architecture of interphase chromosomes and gene positioning are altered by changes in DNA methylation and histone acetylation. J Cell Sci 115:45974605 (2002).

Santos AP, Ferreira L, Maroco J, Oliveira MM: Abiotic stress and induced DNA hypomethylation cause interphase chromatin structural changes in rice rDNA loci. Cytogenet Genome Res 132:297-303 (2011).

-Silva M, Pereira HS, Bento M, Santos AP, Shaw $\mathrm{P}$, et al: Interplay of ribosomal DNA loci in nucleolar dominance: dominant NORs are up-regulated by chromatin dynamics in the wheat-rye system. PLoS One 3:e3824 (2008).

Swindell WR, Huebner M, Weber AP: Transcriptional profiling of Arabidopsis heat shock proteins and transcription factors reveals extensive overlap between heat and non-heat stress response pathways. BMC Genomics 8:125 (2007).

Tamura K, Peterson D, Peterson N, Stecher G, Nei M, et al: MEGA5: Molecular evolutionary genetics analysis using maximum likelihood, evolutionary distance, and maximum parsimony methods. Mol Biol Evol 28:27312739 (2011).

Tittel-Elmer M, Bucher E, Broger L, Mathieu O, Paszkowski J, Vaillant I: Stress-induced activation of heterochromatic transcription. Plos Genet 6:e1001175 (2010).

Tomita M, Kuramochi M, Iwata S: Superior: a novel repetitive DNA element dispersed in the rye genome. Cytogenet Genome Res 125: 306-320 (2009).

Vershinin AV, Schwarzacher T, Heslopharrison JS: The large-scale genomic organization of repetitive DNA families at the telomeres of rye chromosomes. Plant Cell 7:1823-1833 (1995).

-Vershinin AV, Alkhimova EG, HeslopHarrison JS: Molecular diversification of tandemly organized DNA sequences and heterochromatic chromosome regions in some Triticeae species. Chromosome Res 4:517-525 (1996).

Wu TY, Wang YX, Wu R: Transcribed repetitive DNA-sequences in telomeric regions of rice (Oryza sativa). Plant Mol Biol 26:363-375 (1994).

Zeller G, Henz SR, Widmer CK, Sachsenberg T, Ratsch G, et al: Stress-induced changes in the Arabidopsis thaliana transcriptome analyzed using whole-genome tiling arrays. Plant J 58:1068-1082 (2009). 